\title{
ANALISIS PENGEMBANGAN POTENSI WISATA BUKIT AITUMERI KABUPATEN TELUK WONDAMA
}

\section{(Potential Development Analysis of Bukit Aitumeri Tourist Attraction in Teluk Wondama)}

\author{
Cahya. D.R.F Burami ${ }^{1}$, Yohanes Y. Rahawarin ${ }^{1 凶}$ dan Mariana H. Peday ${ }^{1}$ \\ Jurusan Kehutanan, Fakultas Kehutanan Universitas Papua Manokwari, Papua Barat, \\ 98314. Tlp/Fax: +62986211065. \\ ${ }^{\square}$ Penulis Korespondensi: Email: yohanis.y.rahawarin@yahoo.com \\ Diterima: 21 Mar 2017| Disetujui: 15 Apr 2017
}

\begin{abstract}
Abstrak
Penelitian ini bertujuan untuk mengetahui jenis-jenis daya tarik wisata yang terdapat di Bukit Aitumeri dan mengetahui faktor-faktor yang menjadi kendala dalam pengembangan potensi wisata serta alternatif strategi pengembangan ODTW Bukit Aitumeri. Metode yang digunakan dalam penelitian ini adalah metode deskriptif dengan teknik observasi lapang. Data yang diperoleh kemudian dianalisis faktor internal (kekuatan, kelemahan), dan faktor eksternal (peluang, ancaman) yang ada dengan menggunakan analisis SWOT. Hasil penelitian menunjukkan situasi yang sangat menguntungkan dimana kawasan ini memiliki peluang dan kekuatan yang besar maka pengembangan wisata di Kabupaten Teluk Wondama khususnya di Kampung Miei (Maniwak) mengenai kawasan Bukit Aitumeri dapat dilaksanakan dengan memanfaatkan peluang yang ada. Sejalan dengan perkembangan wilayah maka perlu dibuat strategi yang saling berkaitan antara faktor internal dan eksternal guna mendukung proses pengembangan wisata di kawasan Bukit Aitumeri kampung Miei (Maniwak).
\end{abstract}

Kata Kunci: Potensi wisata, daya tarik, analisis SWOT, Bukit Aitumeri.

\begin{abstract}
This study aimed to know types of tourist attractions in Bukit Aitumeri and determine deterrent factors in tourism potential development as well as alternative strategy for the development of Bukit Aitumeri tourist attraction. Method applied in the study was descriptive through field observation technique. Data gathered then analyzed for its internal (strength and weakness) and external (opportunity and threat) factors by applying SWOT analysis. The result showed a very beneficial circumstance in which the area possessed a number of positive opportunities and strengths. Such a condition, will boost the development of several potential tourism attractions in Teluk Wondama District in particular Miei village (Maniwak). In line with regional development program, then a binding strategy between internal and external factors was needed in order to keep up tourist development in the Bukit Aitumeri area of Miei village (Maniwak).
\end{abstract}

Keywords: tourism potential, attraction, SWOT analysis, Bukit Aitumeri. 


\section{PENDAHULUAN}

Pariwista adalah berbagai macam kegiatan wisata dan didukung oleh berbagai fasilitas serta layanan yang disediakan masyarakat, pengusaha, pemerintah pusat, dan pemerintah daerah (UU No. 10 Tahun 2009). Pengembangan kepariwisataan di Indonesia saat ini semakin penting tidak saja dalam rangka meningkatkan penerimaan devisa negara, diharapkan juga dapat memperluas kesempatan berusaha, disamping memberikan lapangan pekerjaan baru untuk mengurangi pengangguran. Pengembangan pariwisata itu harus direncanakan secara baik, karena tanpa ada rencana yang matang, dikhawatirkan pariwisata sebagai suatu industri akan memberikan dampak yang tidak menguntungkan (Hidayat 2011; Badarab dkk. 2017).

Kepariwisataan merupakan bagian dari fenomena sosial, ekonomi, psikologi, geografi dan budaya. Aspek sosial pariwisata adalah kebutuhan dasar manusia untuk menjalin hubungan dengan orang lain, sedangkan aspek ekonomi adalah pariwisata dapat meningkatkan pendapatan masyarakat setempat, pemerintah setempat, pedagang kecil dan lain sebagainya. Berdasarkan aspek psikologi, pariwisata menjadi sarana untuk memulihkan kesehatan moral seseorang, sedangkan dari segi geografis, pariwisata merupakan fenomena geografi artinya penampakan geografis yang khusus akan menjadi daya tarik bagi wisatawan. Aspek budaya pariwisata memberikan daya tarik kepada wisatawan sehingga termotivasi dan berkeinginan untuk melihat dan mengenal suatu kebudayaan bangsa lain (Soin 2012).
Upaya meningkatkan peran kepariwisataan sangat terkait antara barang berupa obyek wisata sendiri yang dapat dijual dengan sarana dan prasarana yang mendukungnya yang terkait dalam industri pariwisata. Usaha mengembangkan suatu daerah tujuan wisata harus memperhatikan berbagai faktor yang berpengaruh terhadap keberadaan suatu daerah tujuan wisata (Ayati 2013).

Sektor pariwisata saat ini telah menjadi andalan untuk sumber pendapatan di beberapa daerah di Indonesia seperti di Provinsi Bali dan Nusa Tenggara Barat. Berbeda dengan daerah tersebut, di tanah Papua sendiri sektor ini belum sepenuhnya memberikan kontribusi yang signifikan bagi daerah dan kesejahteraan masyarakat. Hal ini disebabkan oleh kurangnya perencanaan strategis dalam pembangunan pariwisata di tanah Papua. Perencanaan pembangunan sektor pariwisata di suatu daerah dibutuhkan ketersediaan data dan informasi yang memadai, karena tanpa hal ini niscaya perencanaan tidak akan menghasilkan sebuah dokumen yang baik (Widiati 2016). Beberapa hal yang perlu disiapkan dalam menyusun rencana strategis sektor pariwisata di suatu daerah dapat berupa pemetaan potensi dan strategi pengembangan wisata.

Kabupaten Teluk Wondama merupakan salah satu kabupaten pemekaran yang ada di Provinsi Papua Barat dan memiliki banyak potensi wisata serta objek wisata yang menarik. Keanekaragaman flora dan fauna serta pemandangan alam yang sangat indah unik dan khas baik di darat maupun bawah laut, sangat potensial bagi pengembangan wisata alam maupun wisata bahari. Selain itu Teluk Wondama 
memiliki keunikan kultur budaya, adatistiadat masyarakat asli serta beberapa peninggalan sejarah masa lalu, yang mana potensi ini sangat mendukung untuk menarik wisatawan berwisata budaya dan sejarah. salah satunya adalah wisata budaya di kawasan Bukit Aitumeri. Penelitian ini bertujuan untuk mengetahui jenis-jenis daya tarik wisata yang terdapat di Bukit Aitumeri, mengetahui faktorfaktor yang menjadi kendala dalam pengembangan potensi wisata Bukit Aitumeri, dan mengetahui alternatif strategi pengembangan ODTW Bukit Aitumeri.

\section{METODE PENELITIAN}

Penelitian ini dilaksanakan pada kawasan bukit Aitumeri yang terletak di Kampung Miei (Maniwak) Distrik Wasior Kota Kabupaten Teluk Wondama selama \pm 2 minggu pada bulan Mei 2013. Yang menjadi obyek dalam penelitian ini adalah Kawasan Bukit Aitumeri, sedangkan Subyek penelitian ini yaitu responden kunci meliputi tokoh masyarakat/adat, pejabat instansi terkait, tokoh keagamaan.

\section{Metode dan Teknik Penelitian}

Metode yang digunakan dalam penelitian ini adalah metode deskriptif dengan teknik observasi lapang. Metode deskriptif merupakan metode penelitian untuk membuat gambaran mengenai situasi. Teknik survei atau observasi dilakukan dengan cara wawancara, dan pengamatan langsung ke lapangan. Dalam kajian ini, variabel yang dilihat yaitu: potensi internal yang meliputi daya tarik utama, daya tarik penunjang kondisi dan kualitas obyek wisata; potensi eksternal yang meliputi aksesibilitas, sarana dan prasarana; serta aspek sosial masyarakat di sekitar kawasan Bukit Aitumeri.

\section{Teknik Penentuan Responden}

Responden terdiri dari responden kunci meliputi tokoh masyarakat/adat meliputi pemilik hak ulayat 1 orang, Kepala Kampung 1 orang, Tokoh Adat 1 orang, Tokoh Keagamaan meliputi Ketua Klasis Wondama dan pejabat dari instansi terkait meliputi, Dinas Pariwisata 1 orang, Dinas Kehutanan 1 orang, Kepala Distrik Wasior Kota 1 orang., Kepala BAPPEDA 1 orang. Responden kunci ini dipilih karena mereka mengetahui dan berperan penting dalam rencana pengembangan potensi wisata di Bukit Aitumeri.

\section{Pengumpulan Data}

Data yang dikumpulkan dalam penelitian ini meliputi data primer dan data sekunder. Data primer meliputi obyek daya tarik wisata yang terdapat di kawasan Bukit Aitumeri, aksesbilitas, serta sarana dan prasarana. Data primer diperoleh dari hasil wawancara dan pengamatan lapangan, hasil wawancara dikumpulkan dengan menggunakan kuisioner serta tape recorder yang telah disiapkan serta dokumentasi obyek wisata dengan menggunakan kamera. Sedangkan data sekunder diperoleh dari studi literatur dengan cara pencarian di internet, studi pustaka dari laporan dan hasil-hasil penelitian sejenis yang berkaitan dengan topik penelitian. Data sekunder ini berupa data penunjang meliputi keadaan umum lokasi penelitian.

\section{Pengolahan dan Analisis Data}

Penelitian ini menggunakan metode analisis deskriptif. Data yang diperoleh kemudian ditabulasi dalam bentuk tabel 
dan gambar, kemudian di analisis faktor internal (kekuatan, kelemahan), dan faktor eksternal (peluang, ancaman) yang ada dengan menggunakan analisis SWOT. Selain itu analisis tersebut juga digunakan untuk mengetahui peluang pengembangan obyek dan daya tarik wisata yang dapat dikembangkan pada Kawasan Bukit Aitumeri Kabupaten Teluk Wondama. Analisis data yang digunakan sebagai berikut:

\section{Analisis Strategi Pengembangan}

Pengolahan dan analisis data menggunakan teknik analisis manajemen SWOT (Sianipar dan Entang 2003), yaitu suatu proses merinci keadaan lingkungan internal dan eksternal guna mengetahui faktor-faktor yang merupakan kunci keberhasilan kedalam kategori kekuatan (strengths), kelemahan (weaknesses), peluang (opportunities), dan ancaman (threats). Metoda analisa SWOT bisa dianggap sebagai metoda analisa yang paling dasar, yang berguna untuk melihat suatu topik atau permasalahan dari empat (4) sisi berbeda. Untuk merumuskan arahan strategi pengembangan ekowisata digunakan pendekatan analisis SWOT. Menurut Rangkuti (2000), analisis SWOT adalah identifikasi berbagai faktor secara sistematis untuk merumuskan strategi pengembangan ekowisata. Analisis ini didasarkan pada logika dan hasil analisa biasanya adalah arahan atau rekomendasi yang dapat memaksimalkan kekuatan (strenghts) dan peluang (opportunities), namun secara bersamaan dapat meminimalkan kelemahan (weaknesses) dan ancaman (threats).

Proses penyusunan perencanaan strategis melalui tiga tahapan yaitu : (1) mengidentifikasi faktor-faktor internal dan eksternal; (2) tahap pengumpulan data yang meliputi penentuan tabel Faktor Strategi Eksternal (EFAS) dan Faktor Strategi Internal (IFAS), (3) Penentuan bobot pada faktor-faktor kekuatan dan kelemahan serta peluang dan ancaman, (4) tahap analisis meliputi penentuan matriks SWOT, penentuan Matriks Grand Strategi, dan pengambilan keputusan.

\section{HASIL DAN PEMBAHASAN}

\section{Rencana Pengembangan}

Berdasarkan hasil diskusi dan persepsi bahwa masyarakat mendukung kebijakan pemerintah dalam rencana pengembangan kawasan Bukit Aitumeri dan mereka memiliki harapan agar Bukit Aitumeri pada masa lampau, sekarang, maupun yang akan datang harus tetap sama seperti semula. Selain itu harapan agar keindahan dan nilai sejarah dari tempat ini tetap ada, terjaga, dan tetap diingat oleh semua orang Papua bahwa tempat ini adalah tempat dimana pertama kali orang Papua mengenal Injil dan pendidikan. Masyarakat juga berharap dengan adanya rencana pengembangan di tempat ini dapat memberikan manfaat ekonomi dan diharapkan pemerintah dapat membuat sarana khusus supaya masyarakat Miei khusunya dan masyarakat Wondama dapat menjual hasil kerajinan tangan maupun hasil bumi Wondama.

\section{Identifikasi Faktor-Faktor Internal Dan Eksternal}

\section{Faktor Internal}

Kekuatan (Strengths), yaitu faktor-faktor yang mempunyai kekuatan peluang pengembangan potensi wisata Bukit Aitumeri, seperti :

1. Tingginya nilai potensi estetika dan sejarah. 
2. Letak strategis dan mudah dijangkau.

3. Masyarakat setempat mendukung sepenuhnya dalam rencana pengembangan Kawasan Bukit Aitumeri. Dan masyarakat siap untuk direlokasi ke tempat lain.

4. Adanya dukungan pemerintah daerah dalam pengembangan Kawasan Bukit Aitumeri.

5. Sudah ada rencana strategis dalam pengembangan Kawasan Bukit Aitumeri.

Kelemahan (weakness), yaitu faktorfaktor yang dianggap menjadi kelemahan dari peluang pengembangan potensi wisata Bukit Aitumeri, seperti :

1. Beberapa bangunan peninggalan sejarah telah rusak termakan usia dan akibat bencana banjir.

2. Belum adanya dukungan sarana dan prasarana umum yang memadai di dalam kawasan Bukit Aitumeri.

3. Jalan menuju Batu Inspirasi memprihatinkan.

4. Kuranganya promosi tentang kawasan wisata budaya dan sejarah Bukit Aitumeri.

\section{Potensi Eksternal}

Peluang (opportunies), yaitu faktor-faktor yang dianggap menjadi peluang pengembangan potensi wisata Bukit Aitumeri, seperti:

1. Bukit Aitumeri dapat menjadi daerah tujuan wisata budaya dan sejarah

2. Pengembangan objek dan daya tarik wisata (ODTW) dapat menjadi sumber pendapatan untuk masyarakat sekitar Kawasan Bukit Aitumeri, Pemerintah serta pihak gereja.

3. Adanya minat serta dukungan masyarakat, pihak gereja dan pemerintah dalam rencana pengembangan situs-situs bersejarah.

4. Dapat menciptakan lapangan pekerjaan bagi masyarakat yang berada di sekitar kawasan Bukit Aitumeri.

Ancaman (threats), yaitu faktor-faktor yang dianggap menjadi ancaman dari rencana pengembangan potensi wisata Bukit Aitumeri seperti:

1. Pembangunan atau perenovasian situs tidak boleh merusak bentuk asli atau nilai sejarah yang ada di dalam kawasan tersebut.

2. Rencana pengembangan potensi wisata yang telah disusun oleh pemerintah terkait, harus dirancang sebaik mungkin dan memperhatikan nilai sejarah yang terkandung didalam situ-situs tersebut, keasrian didalam kawasan tersebut, sehingga nilai-nilai sejarah yang sudah ada sejak jaman zendeling tidak berubah, sehingga ketika pengunjung datang dapat merasakan suasana dahulu.

3. Rencana pembuatan 1000 tangga menuju ke Batu Inspirasi jika tidak dirancang dengan baik maka akan merusak ekosistem dan keasrian daerah tersebut.

4. Akan merusak habitat dari satwasatwa yang berada di sekitar kawasan Bukit Aitumeri.

Tahap-tahap dalam menyusun tabel Internal Factor Analysis Summary (IFAS) dengan menentukan faktor-faktor yang menjadi kekuatan (strength) serta kelemahan (weakness) potensi wisata Bukit Aitumeri. Namun sebelum membuat matriks IFAS faktor internal dan eksternal untuk menentukan bobot dari masingmasing faktor (kekuatan, kelemahan, peluang, ancaman). Menurut Putong (2003) cara menentukan bobot 
setiap indikator dari faktor-faktor internal maupun eksternal yaitu dengan menggunakan skala prioritas mulai dari 4 (sangat penting) sampai dengan 1 (tidak penting) pada variabel bersifat positif. Sedangkan pada variabel bersifat negatif diberi nilai sebaliknya yaitu dari 1 (sangat penting) sampai dengan 4 (tidak penting). Kemudian Kalikan nilai skala prioritas
(SP) dengan konstanta (K). Penentuan nilai konstanta didasarkan pada nilai tertinggi yaitu 4 dengan asumsi bahwa semua indikator dianggap baik. Masingmasing nilai $\mathrm{SP} \times \mathrm{K}$ dibagi dengan total nilai $\mathrm{SP} \times \mathrm{K}$ untuk memperoleh nilai bobot. Penentuan bobot pada faktorfaktor kekuatan dan kelemahan dapat dilihat pada tabel 1.

Tabel 1. Penentuan bobot faktor-Faktor kekuatan dan kelemahan.

$\begin{array}{ccccc}\text { Faktor-Faktor Strategi Internal } & \text { Skala } & \text { Konstanta } & \mathrm{SP} \times & \text { Bobo } \\ & \text { Prioritas } & (\mathrm{K}) & \mathrm{K} & \mathrm{t}\end{array}$

(SP)

\begin{tabular}{|c|c|c|c|c|c|}
\hline \multicolumn{6}{|c|}{ Kekuatan } \\
\hline 1. & Tingginya nilai potensi estetika dan sejarah & 4 & 4 & 16 & 0,22 \\
\hline 2. & Letak strategis dan mudah dijangkau & 3 & 4 & 12 & 0,17 \\
\hline 3. & $\begin{array}{l}\text { Masyarakat setempat mendukung } \\
\text { sepenuhnya dalam rencana pengembangan } \\
\text { Kawasan Bukit Aitumeri, Dan masyarakat } \\
\text { siap untuk di relokasi ke tempat lain. }\end{array}$ & 4 & 4 & 16 & 0,22 \\
\hline 4. & $\begin{array}{l}\text { Adanya dukungan pemerintah daerah dalam } \\
\text { pengembangan Kawasan Bukit Aitumeri }\end{array}$ & 3 & 4 & 16 & 0,22 \\
\hline 5 . & $\begin{array}{l}\text { Sudah ada rencana strategis dalam } \\
\text { pengembangan Kawasan Bukit Aitumeri }\end{array}$ & 4 & 4 & 12 & 0,17 \\
\hline \multicolumn{3}{|c|}{ Total SP/K } & & 72 & 1,0 \\
\hline \multicolumn{6}{|c|}{ Kelemahan } \\
\hline$\overline{1 .}$ & $\begin{array}{l}\text { Beberapa bangunan peninggalan sejarah } \\
\text { telah rusak termakan usia dan akibat bencana } \\
\text { banjir. }\end{array}$ & 1 & 4 & 4 & 0,17 \\
\hline 2. & $\begin{array}{l}\text { Belum adanya dukungan sarana dan } \\
\text { prasarana umum yang memadai didalam } \\
\text { kawasan Bukit Aitumeri. }\end{array}$ & 1 & 4 & 4 & 0,17 \\
\hline 3. & Jalan menuju batu Inspirasi memprihatinkan. & 2 & 4 & 8 & 0,33 \\
\hline & $\begin{array}{l}\text { Kuranganya promosi tentang kawasan wisata } \\
\text { budaya dan sejarah Bukit Aitumeri }\end{array}$ & 2 & 4 & 8 & 0,33 \\
\hline \multicolumn{3}{|c|}{ Total SP/K } & & $\overline{24}$ & 1,0 \\
\hline
\end{tabular}

Berdasarkan tabel 1, penentuan bobot faktor-faktor kekuatan dan kelemahan pada tabel di atas maka dapat dibuat faktor-faktor strategi yang hasilnya ditunjukkan pada Tabel IFAS disusun untuk merumuskan faktor-faktor strategis internal tersebut dalam kerangka kekuatan (strength) dan kelemahan (weakness) dengan menggunakan alur tahapan sebagai berikut: 
1. Tentukan faktor-faktor yang menjadi kekuatan serta kelemahan perusahaan dalam kolom 1.

2. Beri bobot masing-masing faktor tersebut dengan skala mulai dari 1,0 (paling penting) sampai 0,0 (tidak penting), berdasarkan pengaruh faktorfaktor tersebut terhadap posisi strategis perusahaan. (Semua bobot tersebut jumlahnya tidak boleh melebihi skor total 1,00).

Tabel 2. Matriks faktor-faktor strategi internal (IFAS).

\begin{tabular}{|c|c|c|c|}
\hline Faktor-Faktor Strategi Internal & Bobot & Rating & $\begin{array}{c}\text { Bobot } \times \text { Rating } \\
(\text { Skor })\end{array}$ \\
\hline \multicolumn{4}{|l|}{ Kekuatan } \\
\hline 1. Tingginya nilai potensi estetika dan sejarah & 0,22 & 4 & 0,89 \\
\hline 2. Letak strategis dan mudah dijangkau & 0,17 & 4 & 0,67 \\
\hline $\begin{array}{l}\text { 3. Masyarakat setempat mendukung sepenuhnya } \\
\text { dalam rencana pengembangan Kawasan Bukit } \\
\text { Aitumeri, Dan masyarakat siap untuk di } \\
\text { relokasi ke tempat lain. }\end{array}$ & 0,22 & 3 & 0,67 \\
\hline $\begin{array}{l}\text { 4. Adanya dukungan pemerintah daerah dalam } \\
\text { pengembangan Kawasan Bukit Aitumeri }\end{array}$ & 0,22 & 3 & 0,67 \\
\hline $\begin{array}{l}\text { 5. Sudah ada rencana strategis dalam } \\
\text { pengembangan Kawasan Bukit Aitumeri }\end{array}$ & 0,17 & 4 & 0,67 \\
\hline Total SP/K & 1,00 & & 3,56 \\
\hline \multicolumn{4}{|l|}{ Kelemahan } \\
\hline $\begin{array}{l}\text { 1. Beberapa bangunan peninggalan sejarah telah } \\
\text { rusak termakan usia dan akibat bencana banjir. }\end{array}$ & 0,17 & 1 & 0,17 \\
\hline $\begin{array}{l}\text { 2. Belum adanya dukungan sarana dan prasarana } \\
\text { umum yang memadai didalam kawasan Bukit } \\
\text { Aitumeri. }\end{array}$ & 0,17 & 2 & 0,33 \\
\hline 3. Jalan menuju batu Inspirasi memprihatinkan. & 0,33 & 2 & 0,67 \\
\hline $\begin{array}{l}\text { 4. Kuranganya promosi tentang kawasan wisata } \\
\text { budaya dan sejarah Bukit Aitumeri }\end{array}$ & 0,33 & 1 & 0,33 \\
\hline Total SP/K & 1,00 & & 1,50 \\
\hline
\end{tabular}

3. Hitung rating (pada kolom 3) untuk masing-masing faktor dengan memberikan skala mulai dari 4 (outstanding) sampai dengan 1 (poor), berdasarkan pengaruh faktor tersebut terhadap kondisi perusahaan yang bersangkutan. Variabel yang bersifat positif (semua variabel yang masuk kategori kekuatan) diberi nilai mulai dari +1 sampai dengan +4 (sangat baik) dengan membandingkannya dengan rata-rata industri atau dengan pesaing utama. Sedangkan variabel yang bersifat negatif, kebalikannya (Rangkuti 2009).

4. Kalikan bobot pada kolom 2 dengan rating pada kolom 3, untuk memperoleh faktor pembobotan dalam kolom 4. Hasilnya berupa skor pembobotan untuk masing-masing faktor yang nilainya bervariasi mulai 
$\begin{array}{lll}\text { dari } 4,0 \text { (outstanding) sampai dengan } & 1,0 & \text { (poor). }\end{array}$

Tabel 3. Penentuan bobot faktor-faktor peluang dan ancaman.

\begin{tabular}{|c|c|c|c|c|}
\hline Faktor-Faktor Strategi Eksternal & $\begin{array}{l}\text { Skala } \\
\text { Prioritas } \\
\text { (SP) }\end{array}$ & $\begin{array}{c}\text { Konstanta } \\
(\mathrm{K})\end{array}$ & $\begin{array}{c}\mathrm{SP} \times \\
\mathrm{K}\end{array}$ & $\begin{array}{c}\text { Bobo } \\
t\end{array}$ \\
\hline \multicolumn{5}{|l|}{ Kekuatan } \\
\hline $\begin{array}{l}\text { Bukit Aitumeri dapat menjadi daerah tujuan } \\
\text { wisata budaya dan sejarah }\end{array}$ & 4 & 4 & 16 & 0,25 \\
\hline $\begin{array}{l}\text { 2. Pengembangan objek dan daya tarik wisata } \\
\text { (ODTW) dapat menjadi sumber pendapatan } \\
\text { untuk masyarakat sekitar Kawasan Bukit } \\
\text { Aitumeri, Pemerintah serta pihak gereja. }\end{array}$ & 4 & 4 & 16 & 0,25 \\
\hline $\begin{array}{l}\text { 3. Adanya minat serta dukungan masyarakat, } \\
\text { pihak gereja dan pemerintah dalam rencana } \\
\text { pengembangan situs-situs bersejarah. }\end{array}$ & 4 & 4 & 16 & 0,25 \\
\hline $\begin{array}{l}\text { 4. Dapat menciptakan lapangan pekerjaan bagi } \\
\text { masyarakat yang berada di sekitar kawasan } \\
\text { Bukit Aitumeri. }\end{array}$ & 4 & 4 & 16 & 0,25 \\
\hline Total SP/K & & & 64 & 1,00 \\
\hline \multicolumn{5}{|l|}{ Kelemahan } \\
\hline $\begin{array}{l}\text { Pembangunan atau perenovasian situs tidak } \\
\text { boleh merusak bentuk asli atau nilai sejarah } \\
\text { yang ada di dalam kawasan tersebut. }\end{array}$ & 1 & 4 & 4 & 0,20 \\
\hline $\begin{array}{l}\text { 2. Rencana pengembangan potensi wisata } \\
\text { yang telah disusun oleh pemerintah terkait, } \\
\text { harus di rancang sebaik mungkin dan } \\
\text { memperhatikan nilai sejarah yang } \\
\text { terkandung didalam situsitus tersebut, } \\
\text { keasrian didalam kawasan tersebut, } \\
\text { sehingga nilai-nilai sejarah yang sudah ada } \\
\text { sejak jaman Zendeling tidak berubah, dan } \\
\text { ketika pengunjung datang dapat merasakan } \\
\text { suasana pada jaman zendeling dahulu. }\end{array}$ & 2 & 4 & 8 & 0,40 \\
\hline $\begin{array}{l}\text { 3. Rencana pembuatan } 1000 \text { tangga menuju ke } \\
\text { batu inspirasi jika tidak dirancang dengan } \\
\text { baik maka akan merusak ekosistem dan } \\
\text { keasrian daerah tersebut. }\end{array}$ & 1 & 4 & 4 & 0,20 \\
\hline $\begin{array}{l}\text { 4. Akan merusak habitat dari satwa-satwa } \\
\text { yang berada di sekitar kawasan bukit } \\
\text { aitumeri. }\end{array}$ & 1 & 4 & 4 & 0,20 \\
\hline Total SP/K & & & 20 & 1,00 \\
\hline
\end{tabular}


5. Jumlahkan skor pembobotan (pada kolom 4), untuk memperoleh total skor pembobotan bagi perusahaan yang bersangkutan. Nilai total ini menunjukkan bagaimana perusahaan tertentu bereaksi terhadap faktorfaktor strategis internalnya.

Menurut Putong (2003) bahwa cara menentukan bobot setiap indikator dari faktor-faktor internal maupun eksternal yaitu dengan menggunakan skala prioritas mulai dari 4 (sangat penting) sampai dengan 1 (tidak penting) pada variabel bersifat positif. Sedangkan pada variabel bersifat negatif diberi nilai sebaliknya yaitu dari 1 (sangat penting) sampai dengan 4 (tidak penting). Kemudian Kalikan nilai skala prioritas (SP) dengan

Menurut Putong (2003) bahwa cara menentukan bobot setiap indikator dari faktor-faktor internal maupun eksternal yaitu dengan menggunakan skala prioritas mulai dari 4 (sangat penting) sampai dengan 1 (tidak penting) pada variabel bersifat positif. Sedangkan pada variabel bersifat negatif diberi nilai sebaliknya yaitu dari 1 (sangat penting) sampai dengan 4 (tidak penting). Kemudian Kalikan nilai skala prioritas (SP) dengan konstanta (K). Penentuan nilai konstanta didasarkan pada nilai tertinggi yaitu 4 dengan asumsi bahwa semua indicator dianggap baik. Masing-masing nilai SP $\times$ $\mathrm{K}$ dibagi dengan total nilai $\mathrm{SP} \times \mathrm{K}$ untuk memperoleh nilai bobot.

Berdasarkan tabel faktor-faktor peluang dan ancaman pada tabel diatas, maka dapat dibuat faktor-faktor strategis yang hasilnya ditunjukkan pada tabel berikut ini dan tabel disusun untuk merumuskan faktor-faktor strategis eksternal tersebut dalam kerangka peluang (opportunities) ancaman (threats) konstanta (K). Penentuan nilai konstanta didasarkan pada nilai tertinggi yaitu 4 dengan asumsi bahwa semua indicator dianggap baik. Masing-masing nilai SP $\times$ $\mathrm{K}$ dibagi dengan total nilai $\mathrm{SP} \times \mathrm{K}$ untuk memperoleh nilai bobot.

\section{Matriks Faktor Strategi Eksternal (EFAS)}

Tahap-tahap dalam menyusun tabel Internal Factor Analysis Summary (IFAS) dengan menentukan faktor-faktor yang menjadi peluang (opportunity) serta ancaman (threat) kawasan Bukit Aitumeri. Namun sebelum membuat matriks EFAS internal dan eksternal untuk menentukan bobot dari masingmasing faktor, dapat dilihat pada tabel 4., perusahaan dengan tahapan sebagai berikut:

1. Tentukan faktor-faktor yang menjadi peluang serta ancaman dalam kolom 1 .

2. Beri bobot masing-masing faktor tersebut dengan skala mulai dari 1,0 (paling penting) sampai 0,0 (tidak penting). Faktor-faktor tersebut kemungkinan dapat memberikan dampak terhadap faktor strategis.

3. Hitung rating (pada kolom 3) untuk masing-masing faktor dengan memberikan skala mulai dari 4 (outstanding) sampai dengan 1 (poor), berdasarkan pengaruh faktor tersebut terhadap kondisi perusahaan yang bersangkutan. Variabel yang bersifat positif (semua variabel yang masuk kategori peluang) diberi nilai mulai dari +1 sampai dengan +4 (sangat baik) Sedangkan variabel yang bersifat negatif (semua variabel yang masuk kategori ancaman), kebalikannya atau diberi nilai mulai dari 4 (tidak baik) sampai dengan 1 (sangat baik) (Rangkuti 2009). 
4. Kalikan bobot pada kolom 2 dengan rating pada kolom 3, untuk memperoleh faktor pembobotan dalam pembobotan untuk masing-masing faktor yang nilainya bervariasi mulai dari 4,0 (outstanding) sampai dengan 1,0

(poor).

Tabel 4. Matriks faktor-faktor strategi eksternal (IFAS).

Faktor-Faktor Strategi Eksternal

Bobot

0,25

0,25

wisata budaya dan sejarah

2. Pengembangan objek dan daya tarik wisata (ODTW) dapat menjadi sumber pendapatan untuk masyarakat sekitar Kawasan Bukit Aitumeri, Pemerintah serta pihak gereja.

3. Adanya minat serta dukungan masyarakat, pihak gereja dan pemerintah dalam rencana pengembangan situs-situs bersejarah.

4. Dapat menciptakan lapangan pekerjaan bagi masyarakat yang berada di sekitar kawasan Bukit Aitumeri.

\begin{tabular}{|c|c|c|c|}
\hline Total SP/K & 1,00 & & 3,75 \\
\hline \multicolumn{4}{|l|}{ Ancaman } \\
\hline $\begin{array}{l}\text { 1. Pembangunan atau perenovasian situs tidak } \\
\text { boleh merusak bentuk asli atau nilai sejarah } \\
\text { yang ada di dalam kawasan tersebut. }\end{array}$ & 0,20 & 1 & 0,20 \\
\hline $\begin{array}{l}\text { 2. Rencana pengembangan potensi wisata yang } \\
\text { telah disusun oleh pemerintah terkait, harus di } \\
\text { rancang sebaik mungkin dan memperhatikan } \\
\text { nilai sejarah yang terkandung didalam situ-situs } \\
\text { tersebut, keasrian didalam kawasan tersebut, } \\
\text { sehingga nilai-nilai sejarah yang sudah ada } \\
\text { sejak jaman Zendeling tidak berubah, dan } \\
\text { ketika pengunjung datang dapat merasakan } \\
\text { suasana pada jaman zendeling dahulu. }\end{array}$ & 0,40 & 2 & 0,80 \\
\hline $\begin{array}{l}\text { 3. Rencana pembuatan } 1000 \text { tangga menuju ke } \\
\text { batu inspirasi jika tidak dirancang dengan baik } \\
\text { maka akan merusak ekosistem dan keasrian } \\
\text { daerah tersebut. }\end{array}$ & 0,20 & 2 & 0,40 \\
\hline \multirow{2}{*}{$\begin{array}{l}\text { 4. Akan merusak habitat dari satwa-satwa yang } \\
\text { berada di sekitar kawasan bukit aitumeri } \\
\text { Total } \mathrm{SP} / \mathrm{K}\end{array}$} & 0,20 & 1 & 0,20 \\
\hline & 1,00 & & 1,60 \\
\hline
\end{tabular}

$\begin{array}{lll}0,25 & 4 & 1\end{array}$

$\begin{array}{lll}0,25 & 4 & 1\end{array}$

Kekuatan 
5. Jumlahkan skor pembobotan (pada kolom 4), untuk memperoleh total skor pembobotan bagi perusahaan yang bersangkutan. Nilai total ini menunjukkan bagaimana Perusahaan tertentu bereaksi terhadap faktorfaktor strategis eksternalnya.

\section{Matriks Grand Strategi/ Diagram SWOT}

Setelah mendapatkan angka dari perhitungan IFAS dan EFAS kemudian dimasukkan ke dalam matriks grand strategi pada Gambar 1. Untuk menentukan posisi kawasan Bukit Aitumeri itu sendiri yang ditunjukkan oleh titik $\mathrm{X}$ dan $\mathrm{Y}$ pada matriks grand strategi /diagram $\quad$ SWOT.

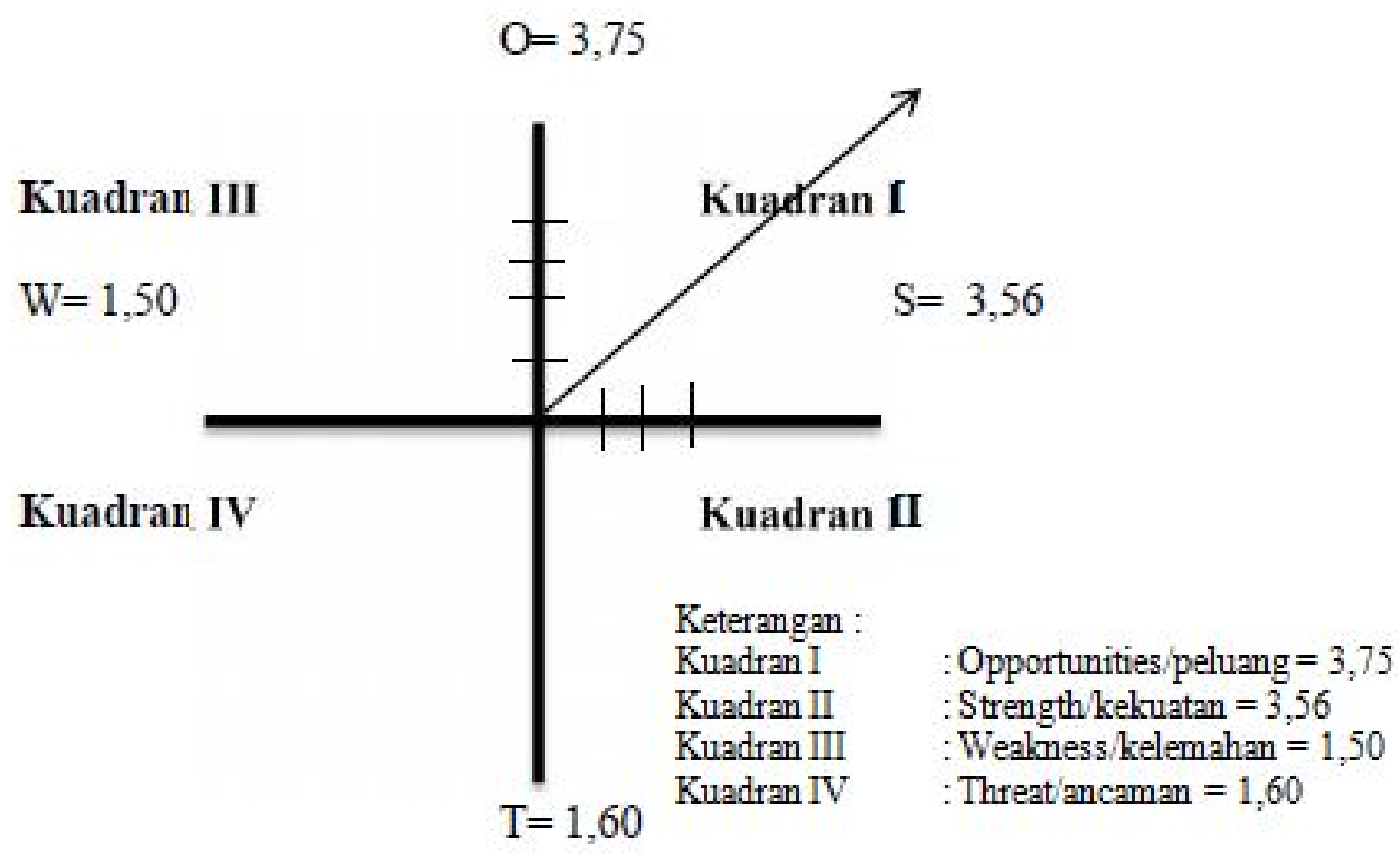

Gambar 1. Diagram hasil analisis SWOT dan tren nilai dari masing-masing parameter SWOT.

Pada gambar, dapat dilihat bahwa nilai $\mathrm{S}$ dan $\mathrm{O}$ sangat besar dibandingkan dengan nilai $\mathrm{W}$ dan $\mathrm{T}$ sehingga posisi kawasan Bukit Aitumeri berada pada kuadran 1. Dengan demikian ini merupakan situasi yang sangat menguntungkan dimana kawasan ini memiliki peluang dan kekuatan yang besar maka pengembangan wisata di Kabupaten Teluk Wondama khususnya di Kampung Miei (Maniwak) mengenai kawasan Bukit Aitumeri dapat dilaksanakan dengan memanfaatkan peluang yang ada. Sejalan dengan perkembangan wilayah maka perlu dibuat strategi yang saling berkaitan antara faktor internal dan eksternal guna mendukung proses pengembangan wisata di kawasan Bukit Aitumeri kampung Miei (Maniwak). 


\section{Kebijakan Dan Strategi Pengembangan Wisata}

Pengembangan wisata di kawasan Bukit Aitumeri pada intinya adalah untuk mengangkat kembali nilai-nilai sejarah ada, mempertahankan situs-situs yang ada, meningkatkan ekonomi masyarakat dan kesejahteraan masyarakat, agar dalam pengembangannya berjalan dengan aman, ramah lingkungan, dan semua pihak dilibatkan dalam pengelolaan. Dari hasil analisis SWOT menghasilkan 4 (empat) kemungkinan alternatif, yaitu:

1. Strategi SO (strength and opportunities), yaitu strategi yang mengoptimalkan kekuatan (strength) untuk memanfaatkan peluang (opportunities), ialah:

a. Menawarkan paket wisata rohani seperti, kunjungan ke situs-situs bersejarah (batu peradaban, sekolah, rumah Pdt.I.S.Kijne, Aula, jembatan gantung, Batu Inspirasi dll).

b. Dapat menarik minat masyarakat maupun wisatawan untuk mendatangi obyek wisata ini, selain dari faktor terpenting yaitu sejarah yang harus diangkat, strategi lain yang harus dilakukan adalah dengan membangun

c. Gedung-gedung pendukung maupun bangunan lain yang dapat menjadi simbol maupun kebanggaan daerah, untuk itu diperlukan bangunan yang dapat menjadi pusat perhatian. Sesuai dengan sejarahnya maka harus dibangun sebuah monumen atau patung seorang I.S.Kijne yang cukup tinggi agar dapat dilihat dari kejauhan dan sebagai bentuk penghormatan kepada "tokoh
Pendidik dan Bapak GKI di Tanah Papua" yaitu Isaak Samuel Kijne.

d. Rencana pengembangan yang telah dirangcang oleh pemerintah harus segera direalisasikan agar masyarakat dapat mendapatkan kejelasan mengenai kawasan Bukit Aitumeri.

e. Pemerintah harus menyediakan sarana khusus supaya masyarakat Miei khususnya dan masyarakat Wondama dapat menjual hasil kerajinan tangan maupun hasil bumi wondama.

2. Strategi WO (weakness and oppotunities), yaitu strategi yang meminimalkan kelemahan untuk memanfaatkan peluang ialah:

a. Dalam pembangunan situs-situs yang sudah rusak, harus dilakukan dengan ramah lingkungan sehingga tidak merusak keindahan kawasan ini, dan pembangunan harus sesuai dengan model bangunan situs pada zaman zendeling sehingga tidak merusak nilai sejarahnya.

b. Pembangunan sarana dan prasarana yang lebih/optimal tanpa merusak lingkungan dan aksesibilitas yang baik sehingga pengunjung dapat menikmati perjalanan wisata.

c. Perlunya peran pemerintah dalam mempromosikan kawasan Bukit Aitumeri sebagai tempat tujuan wisata sejarah.

d. Perlunya melibatkan pejabat Distrik Wasior kota, masyarkat dalam mengambil kebijakan maupun dalam hal pengelolaan kawasan, agar masyarakat dapat bersama-sama memelihara kawasan bersejarah tersebut. 
3. Strategi ST (strength and threats), yaitu strategi yang menggunakan kekuatan untuk mengatasi ancaman,ialah:

a. Pemerintah terkait harus berkoordinasi dengan dinas kehutanan menyangkut status serta pembangunan salah satu situs yang letaknya berbatasan dengan Cagar Alam Wondiboy.

b. Pembangunan fasilitas sarana dan prasarana yang menunjang kawasan Bukit Aitumeri harus melibatkan aparat kampung dan masyarkat serta pengelolaand an penjagaan sehingga dapat memotifasi masyarakat utnuk ikut berperan serta menjaga keamanan di sekitar kawasan Bukit Aitumeri.

c. Memotifasi masyarakat setempat dengan memberikan sosialisasi guna menjaga situs-situs bersejarah serta budaya asli daerah setempat agar tidak terpengaruh budaya asing, dan pemerintah harus segera menyediakan tempat yang layak agar masyarakat yang rumahnya termasuk ke dalam kawasan bukit aitumeri dapat di rekolasi ke tempat yang sesuai dengan kesepakatan bersama.

4. Strategi WT (weakness and threaths), yaitu strategi yang meminimalkan kelemahan dan menghindari ancaman, ialah:

a. Pembangunan fasilitas dan pengelolaan kawasan Bukit Aitumeri perlu direncanakan dengan baik sehingga pembangunan fasilitas pendukung obyek wisata tidak merusak potensi biofisik yang ada. b. Mayarakat lokal diberikan kesempatan untuk ikut berperan dalam pengelolaan kawasan Bukit Aitumeri sebagai obyek wisata unggulan, sehingga merekapun ikut menjaga keamanan serta kenyamanan para pengunjung.

c. Pemerintah terkait seperti dinas pariwisata, BAPPEDA, pihak gereja harus sungguh-sungguh membangun kawasan Bukit Aitumeri ini serta harus ada keterbukaan dan kerjasama dengan baik agar pengembangan obyek wisata Bukit Aitumeri ini dapat meningkatkan taraf hidup masyarakat dan menjadi identitas daerah serta tidak ada yang mengambil keuntungan pribadi dari pengembangan kawasan Bukit Aitumeri.

\section{DAFTAR PUSTAKA}

Ayati 2013. Potensi pengembangan strategi pengembangan ekowisata kupu- kupu sayap burung di Cagar Alam Pegunungan Arfak. (tidak diterbitkan).

Badarab F, Trihayuningtyas E dan Suryadana LM. 2017. Strategi pengembangan destinasi pariwisata di kepulauan Togean Provinsi Sulawesi Tengah. Tourism and Hospitality Essentials Journal, Vol 7(2): 97-112.

Hidayat M. 2011. Strategi perencanaan dan pengembangan objek wisata (studi kasus pantai Pangandaran Kabupaten Ciamis Jawa Barat). Tourism and Hospitality Essentials Journal, Vol 1(1): 33-44.

Putong I. 2003. Teknik pemanfaatan analisis Swot Tanpa skala industri. Fakultas Ekonomi Universitas Bina Nusantara. 
Rangkuti F. 2009. Analisis swot teknik membedah kasus bisnis. PT Gramedia Pustaka Utama. Jakarta

Sianipar JPG dan Entang HM. 2003. Teknik-teknik Analisis manajemen. Lembaga Administrasi Negara. Jakarta

Soin H. 2012. Potensi ekowisata pantai Kabori Distrik Manokwari Selatan Kabupaten Manokwari. (tidak di terbitkan).
Undang-Undang Nomor 10.2019. Kepariwisatan. Kementerian Hukund an Hak Asasi Manusia Republik Indonesia.

Widiati T. 2106. Upaya pengembangan sektor pariwisata dalam meningkatkan pendapatan asli daerah Kabupaten Bulungan. Tugaa Akhir Program Master Universitas Terbuka Jakarta. http://repository.ut.ac.id/6802/1/4226 $\underline{0 . p d f}$. 